Saudi Journal of Medical and Pharmaceutical Sciences

Abbreviated Key Title: Saudi J Med Pharm Sci ISSN 2413-4929 (Print) |ISSN 2413-4910 (Online) Scholars Middle East Publishers, Dubai, United Arab Emirates Journal homepage: http://scholarsmepub.com/sjmps/

Case Report

\title{
Large Early Aneurysm of the Inferior Wall
}

Ballouk R*, Ahchouch S, Ait Kajjate O, Lahlafi Z, Falioun H, Assfaloui I, Raissouni M, Lakhal Z, Benyass A, Zbir E

Heart Center, Mohamed V Military Training Hospital Rabat, Morocco

DOI: $10.36348 /$ SJMPS.2019.v05i10.011

| Received: 16.10.2019| Accepted: 23.10.2019| Published: 30.10.2019

*Corresponding author: Ballouk Ramiz

\section{Abstract}

A left ventricular aneurysm (LVA) is a localized dyskinetic area of infarcted myocardium that bulges in systole and diastole. It is a well studied structural complication seen post myocardial infarction although decreasing in incidence due to major improvements in reperfusion therapy. Persistent ST elevation is the most widely reported electrocardiographic manifestation of left ventricular aneurysms. LVA may be evident on chest x-ray, as observed in this case. Diagnosis is non invasively confirmed using echocardiography. Complications of LVA include congestive heart failure, ventricular arrhythmias and rupture that can lead to sudden cardiac death. Surgical treatment is usually effective and followed by a marked improvement in function but is burdened with a heavy post operative mortality. We report the case of a 55-yearold man, with a history of myocardial infarction presenting with a large left ventricular aneurysm.

Keywords: Ventricular wellstudied dyskinetic.

Copyright @ 2019: This is an open-access article distributed under the terms of the Creative Commons Attribution license which permits unrestricted use, distribution, and reproduction in any medium for non-commercial use (NonCommercial, or CC-BY-NC) provided the original author and source are credited.

\section{INTRODUCTION}

A left ventricular aneurysm is a structural complication observed after myocardial infarction. It's incidence however has decreased due to improvements in reperfusion techniques. It is a dyskinetic zone located at the infarcted myocardium level which is expressed in both systole and diastole. Its complications include congestive heart failure, ventricular arrhythmias, thrombosis and embolism, or rupture leading to sudden death. The abnormality is suspected in the presence of persistent elevation of the ST segment beyond 3 weeks on the electrocardiogram. The diagnosis is confirmed non-invasively by echocardiography. The LVA poses a problem of medical management because, the surgical indication is difficult to carry and the operative result is not always satisfactory.

The prevention of LVA post myocardial infarction is currently significantly improved by early revascularization techniques, as well as early prescription of conversion enzyme inhibitors or angiotensin II receptor antagonists.

\section{OBSERVATION}

We report the case of a 55-year-old patient with the only active cardiovascular risk factor is smoking with an antecedent of amputation of the left leg in 2016 for oblitering arteopathy of lower linb (undocumented). This patient had showed up for management of ischemic cerebral vascular problem occurring a week after a neglected infactoid scene. The examinations carried out had revealed an aneurysm of the inferior wall complicated with thrombus. The evolution was marked 15 days later by the occurrence of a heart failure complicating a reduced ventricular tachycardia.

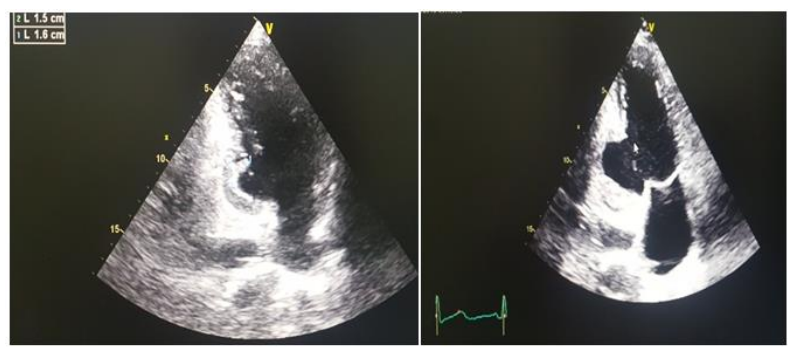

Huge aneurysm of the inferorir wall

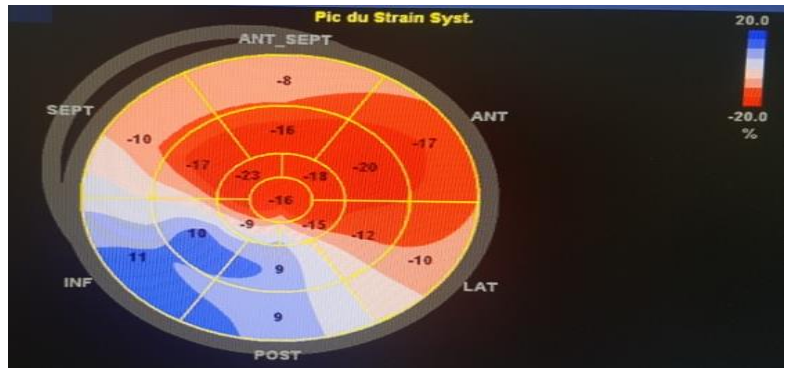

Longitudinal myocardial strain alteration 


\section{DISCUSSION}

LVA is a rare complication of myocardial infarction, with a historical incidence of about $7 \%$. However, given the current management of infarction with early revascularization, its incidence has decreased considerably. The majority of aneurysms are located in the anterolateral wall $(85 \%)$, and much more rarely at the posterior wall. LVA can lead to heart failure by several mechanisms (paradoxical ventricular contraction, mitral regurgitation by distal papillary muscles) and embolic complications (coronary or systemic) due to a frequent mural thrombus associated. Ventricular arrhythmias are also present in 15 to $30 \%$ of LVA, especially when the septum is involved. They are generally resistant to any drug therapy.

Echocardiography remains the test of choice in the diagnosis and evaluation of ventricular aneurysm which appears as a pocket developed in the territory of the myocardial infraction and which communicates with the left ventricle by a wide neck, this pocket whose wall is thin and deforms the left ventricular cavity in diastole, is animated by a dyskinetic contraction in systole. The adoption of these diagnostic criteria makes it possible to distinguish between ventricular aneurysm and other related situations such as akinesia or dyskinesia patches that can be seen in recent transmural myocardial infraction, but where ventricular contour occurs only in systole, or false aneurysms of the left ventricle. This is an essential examination not only for the precise diagnosis but especially for the etiological and prognostic information it provides. It gives information on cavitary dilatation, systolic and diastolic function, pulmonary arterial pressure, mitral and tricuspid leakage and above all the presence of spontaneous contrast or intra-left ventricle thrombus.

The therapeutic approach of left ventricular aneurysm is based on the surgical procedure by ablation of the aneurysmal pocket. Although some authors in the literature, subject of much controversy, advocate starting with medical treatment. In addition, the operative indication on LVA is always difficult to carry; it involves a fairly heavy mortality especially if the patient has decompensated heart failure or has rhythm disorders. If the operative course is crossed, the operative result is not always brilliant. The indication is more difficult to take that the natural evolution does not seem so catastrophic. Currently the use of surgery is limited to patients with heart failure resistant to usual treatments or having rhythm disturbances rebellious to betablocking and antiarrhythmic treatments.

\section{CONCLUSION}

Left ventricular aneurysm is a mechanical complication of myocardial infraction witch poses problem of medical care. The surgical indication is difficult to carry and the operative result is not always brilliant. The prevention of LVA post myocardial infarction is currently significantly improved by early revascularization techniques for myocardial infarction, as well as early prescription of converting enzyme inhibitors or angiotensin receptor antagonists II.

\section{REFERENCES}

1. Ba'Albaki, H. A., \& Clements Jr, S. D. (1989). Left ventricular aneurysm: a review. Clinical cardiology, 12(1), 5-13.

2. Letac, B., Leroux, G., Cribier, A., \& Soyer, R. (1978). Large ventricular aneurysms occurring after myocardial infarction. Heart, 40(5), 516-522.

3. Cohen, M. A. R. C., Packer, M. I. L. T. O. N., \& Gorlin, R. I. C. H. A. R. D. (1983). Indications for left ventricular aneurysmectomy. Circulation, 67(4), 717-722.

4. Lundblad, R., Abdelnoor, M., \& Svennevig, J. L. (2003). Repair of left ventricular aneurysm: surgical risk and long-term survival. The Annals of thoracic surgery, 76(3), 719-725.

5. Letac, B., Leroux, G., Cribier, A., \& Soyer, R. (1978). Large ventricular aneurysms occurring after myocardial infarction. Heart, 40(5), 516-522.

6. Malcolm, I. D., Fitchett, D. H., Stewart, D., Marpole, D., \& Symes, J. (1980). Ventricular aneurysm: false or true? An important distinction. The Annals of thoracic surgery, 29(5), 474-477.

7. Miller, J. M., Kienzle, M. G., Harken, A. H., \& Josephson, M. E. (1984). Subendocardial resection for ventricular tachycardia: predictors of surgical success. Circulation, 70(4), 624-631.

8. Lundblad, R., Abdelnoor, M., \& Svennevig, J. L. (2003). Repair of left ventricular aneurysm: surgical risk and long-term survival. The Annals of thoracic surgery, 76(3), 719-725.

9. Cohen, M. A. R. C., Packer, M. I. L. T. O. N., \& Gorlin, R. I. C. H. A. R. D. (1983). Indications for left ventricular aneurysmectomy. Circulation, 67(4), 717-722.

10. Nagle, R. E., \& Williams, D. O. (1974). Proceedings: Natural history of ventricular aneurysm without surgical treatment. British heart journal, 36(10), 1037-1037.

11. Cohen, M., Wiener, I., Pichard, A., Holt, J., Smith Jr, H., \& Gorlin, R. (1983). Determinants of ventricular tachycardia in patients with coronary artery disease and ventricular aneurysm: Clinical, hemodynamic, and angiographic factors. The American journal of cardiology,51(1), 61-64. 